10.1590/1980-6248-2015-0114

DOSSIÊ “Literatura, infância e espaços escolares”

\title{
Literatura infantil em uma sociedade pós-literária: a dupla morfologia de um sistema cultural em movimento
}

\section{Children's literature in a post-literary society: a double morphology of a changing cultural system}

Rildo Cosson*

*Câmara dos Deputados, Centro de Formação Treinamento e Aperfeiçoamento, Praça dos Três poderes, Esplanada dos Ministérios, Brasília, DF, Brasil. rcosson@gmail.com

UFMG. FAE. Centro de Alfabetização, Leitura e Escrita. Av. Antônio Carlos, 6627, Campus Pampulha, Belo Horizonte, MG, Brasil.

\begin{abstract}
Resumo
Em uma sociedade com profundas transformações tecnológicas e culturais, que modificam não apenas as relações entre as artes, mas também as relações que os indivíduos têm com o mundo simbólico, qual é o lugar do leitor? Como formar um leitor atualmente? Qual a razão para se continuar a ensinar literatura? Partindo de pressupostos teóricos da educação comparada, da teoria dos polissistemas e do letramento literário, buscar-se-á encontrar caminhos de respostas a essas questões, analisando duas configurações paradigmáticas da literatura infantil: as relações com a escola e o livro e, com eles, o processo de aprendizagem da escrita e da formação do leitor, com o objetivo de oferecer, a partir da posição ocupada pelo sistema literário infantil, um horizonte de reflexão sobre o ensino da literatura e a formação do leitor em nossa sociedade pós-literária.

Palavras-chave: literatura infantil, formação do leitor, ensino de literatura.
\end{abstract}




\title{
pro.posições
}

\begin{abstract}
In a society with deep technological and cultural transformations that change not only the relationship between the arts, but also the relationships that individuals have with the symbolic world, which is the place of the reader? How to educate a reader today? What is the reason to keep teaching literature? Starting from theoretical assumptions of comparative education, the theory of polysystem and the literary literacy, we will seek to find paths to answer these questions by analyzing two paradigmatic patterns of children's literature. The analysis will cover the school and the book and, within them, the learning process of writing and of reader's education with the purpose of offering, from the children's literary system location, a horizon of reflection on the teaching of literature and the reader's education in our post-literate society.

Keywords: children's literature, reader's education, teaching literature.
\end{abstract}

A literatura é, dessa maneira, concebida não como uma atividade isolada na sociedade, regulada por leis exclusivamente (e inerentemente) diferentes de todo o resto das atividades humanas, mas sim como um fator integral - frequentemente central e muito poderosoentre essas atividades'.

Itamar Even-Zohar

Em Regras para o parque bumano - uma resposta à carta de Heidegger sobre o bumanismo, um texto que causou forte polêmica no ambiente filosófico (Marques, 2002), o filósofo alemão Peter Sloterdjik (2000) faz referência à nossa sociedade como uma sociedade pós-literária. Para ele, o conhecimento de um cânone literário que caracterizava o letrado da sociedade burguêsnacionalista perdeu o sentido em uma sociedade de massas em que vivemos atualmente. Desse modo, o lugar da escrita, do livro e da literatura (em sentido lato) agora é outro, e a sociedade se organiza em novas bases, "que são decididamente pós-literárias, pós-epistolares e, consequentemente, pós-humanistas", uma vez que "é apenas marginalmente que os meios literários, epistolares e humanistas servem às grandes sociedades modernas para a produção de suas sínteses políticas e culturais" (Sloterdjik, 2000, p. 14). A discussão proposta por Sloterdjik não é sobre a literatura no sentido estreito, mas sim sobre a concepção de humanismo da qual

\footnotetext{
${ }^{1}$ Os textos em língua inglesa foram todos traduzidos por nós.
} 


\section{pro.posições}

a leitura e o apreço às obras canônicas eram manifestações. Interessa-nos, entretanto, ao apropriarmo-nos do termo cunhado pelo filósofo, destacar a reflexão que assinala que vivemos uma nova época e apontar que uma de suas marcas é o deslocamento para a margem ou a perda de hegemonia de uma tradição cultural baseada no cultivo das Letras.

Nesse sentido, o termo "sociedade pós-literária" vem se juntar a vários outros, tais como "sociedade da informação" (Castells, 1999; Masuda, 1980; Mattelart, 2002), "sociedade do conhecimento" ou "pós-industrial" (Bell, 1974; Drucker, 1997; Touraine, 1970) e até “sociedade da ignorância" (Mayos \& Brey, 2011). São expressões que associam as mudanças tecnológicas, econômicas e culturais - sobretudo o uso da Internet, cuja expansão se dá a um ritmo impressionante desde o final do século passado, atingindo virtualmente a todas as manifestações do pensamento humano - com uma nova forma de organização ou modelo de sociedade.

Independentemente se eufóricas, cautelosas, equilibradas ou apocalíticas, as descrições desse novo estágio cultural ou social se erigem a partir de um mesmo pressuposto: a herança do passado, que nos ajudava a entender e a agir no presente, encontra-se esgotada; e é preciso reconhecer (e se adaptar a/ou contestar) o novo momento que se vive, em sua complexidade, para projetar um futuro melhor ou evitar um futuro indesejado. Esse presente-transição, que não pode se apoiar no passado, mas, paradoxalmente, ainda depende dele para ser identificado (não é sem razão o uso alargado do prefixo "pós-"), tem como identidade recorrente o impacto que as transformações tecnológicas trazem não só para a economia, a ciência e as artes, mas também para as relações que os indivíduos mantêm entre si e com o mundo simbólico, justificando a ideia de que não se trata apenas de uma transformação de ordem econômica ou tecnológica, mas também cultural - daí merecer o termo mais amplo: "sociedade".

Tomando, por um lado, o pressuposto de que vivemos em uma sociedade pósliterária, ou seja, uma sociedade na qual a escrita já não ocupa uma posição central, nem a literatura, enquanto linguagem veiculada pelos livros, é sua expressão cultural hegemônica; e, por outro, considerando que o uso intensivo dos novos recursos disponibilizados via Internet também modifica a literatura e o modo como nos relacionamos com ela, questões fulcrais se colocam para quem estuda e trabalha com o tema: qual é o lugar do leitor nessa sociedade? Como formar um leitor atualmente? Qual a razão para se continuar a ensinar literatura? Não 


\section{pro.posições}

temos respostas para essas questões, e este estudo não pretende respondê-las, até porque não acreditamos que possam ser respondidas de imediato. Antes, queremos chamar a atenção para a importância e a pertinência delas para todos nós, que estudamos e trabalhamos com a literatura e seu ensino, propondo um horizonte de reflexão que tem como ponto de partida o universo da literatura infantil.

A hipótese é que o sistema literário infantil, até por sua origem e permanente ligação com a escola, ocupa uma posição emblemática em nossa sociedade pós-literária, sendo um espaço privilegiado para se refletir sobre literatura e formação do leitor. Para desenvolver essa hipótese, vamos apresentar duas formas paradigmáticas da literatura infantil, uma do passado e outra do presente, com o objetivo de indicar, pelo contraste e pelo confronto, os caminhos que se apresentam hoje para a leitura da literatura e seu ensino na escola. Nossa reflexão terá apoio em pressuposições e conceitos da educação comparada, representada por Robert Cowen; da teoria dos polissistemas, de Itamar Even-Zohar; do letramento literário, tal como definido por Paulino e Cosson; e usaremos uma obra da literatura infantil e contribuições de outros estudiosos como suporte analítico destes dois momentos da morfologia da literatura infantil: a escola e o livro, ambos em sua preocupação com a aquisição da escrita e a formação do leitor.

\section{O suporte teórico-metodológico}

A questão das relações de 'empréstimos' de ideias, textos e práticas culturais entre duas ou mais sociedades é um tema que perpassa diversos campos, assim como os conceitos e os modos com que se buscou entender essas relações, a exemplo de imitação, influência, dependência, tradução e intertextualidade. No caso da educação comparada, que não sem razão surgiu na segunda metade do século XIX, assim como a literatura comparada, o direito comparado e outras disciplinas, a questão sempre foi uma preocupação central. Nos seus primórdios, a educação comparada procurava identificar caminhos de 'modernização' ou, pelo menos, avanços no campo educacional, correlacionando-os ao desenvolvimento econômico e cultural, pois esse desenvolvimento funcionava como "a garantia da eficiência dum sistema educativo que, por sua vez, quando adoptado por um país podia colocá-lo no caminho certo do progresso" (Ferreira, 2008, p. 126). Todavia, atualmente a situação é bem diferente. Longe de buscar demarcar uma supremacia cultural, "a educação comparada está hoje em dia 


\section{pro.posições}

engajada numa empreitada salutar de reavaliação de seu projeto científico, de redefinição de suas unidades e de suas ferramentas de análise" (Malet, 2004, p. 1.319), por meio da qual se busca entender as relações que se estabelecem entre sistemas educacionais em diferentes contextos.

Um desses projetos é desposado por Robert Cowen, cujos estudos buscam explicar como se efetiva o processo de adoção de um sistema educacional ou alguns de seus aspectos em outro (Larsen, 2010). Para tanto, o autor cunhou a frase "moveu-se, transformou-se", por meio da qual busca sintetizar uma questão teórica fundamental na educação comparada: a mobilidade de ideias, práticas e sistemas educacionais. De acordo com Cowen (2009), nenhum elemento educacional é simplesmente transladado de um contexto para outro: antes passa por um processo de "modelagem" [shape-shifting], que envolve progressivamente a transferência, entendida como "o movimento de uma ideia ou prática educacional no espaço supranacional e transnacional ou internacional"; a tradução, que corresponde à "modelagem das instituições educacionais ou a reinterpretação das ideias educacionais que rotineiramente ocorre com a transferência no espaço; e a transformação, que é, finalmente, "as metamorfoses que a pressão do poder econômico e social dentro da educação impõe àtradução inicial no novo contexto" (p. 14).

O que Cowen diz sobre os sistemas educacionais pode ser igualmente aplicado aos sistemas literários e, em especial, à literatura infantil entre nós. Transferida da Europa para a América Latina, a literatura infantil chegou ao Brasil marcada pelos laços com a literatura oral, o uso escolar e o ensinamento da moral ou dos "bons costumes". Também participou de um projeto de modernização social e educacional em que se demandava a tradução nacional da produção literária para crianças já no início do século XX e tem como marcos do processo de transformação a obra de Monteiro Lobato, não sem razão composta por textos próprios, traduções e adaptações nos anos 1920, e o amadurecimento, conquistado a partir da década de 1970 (Coelho, 1991).

Compreendendo, com Cowen $(2009)^{2}$, que se os sistemas educacionais, ao se moverem, se transformam - "as it moves, it morphs" -, o mesmo acontece com os sistemas culturais, tal como a literatura infantil, precisamos, também, ter claro o que se implica na

\footnotetext{
${ }^{2} \mathrm{O}$ paralelo entre a leitura das transferências de sistemas educacionais proposta por Cowen e a constituição do sistema da literatura infantojuvenil no Brasil poderia ser igualmente estendido para outros conceitos analíticos do autor, tal como o caráter "transitológico" da produção e recepção da literatura infantojuvenil da década de 1970, por exemplo. Todavia, nosso interesse aqui não é realizar uma leitura extensiva da constituição do sistema literário infantojuvenil, mas, como já dito, apenas mostrar como ele nos ajuda a entender questões fundamentais para o ensino da literatura atualmente.
} 


\section{pro.posıções}

denominação da literatura infantil como sistema literário. A concepção da literatura como um sistema pode ter como referência vários autores, a exemplo de Antônio Candido (1975, 1987), quando propõe que um sistema literário é constituído não apenas de autores e obras, mas também de leitores, todos em um processo de comunicação simbólica contínuo. Neste estudo, vamos adotar o conceito defendido por Itamar Even-Zohar (1990, 2010), tanto porque sua reflexão se dá em um contexto similar ao de Cowen na análise de transferências e traduções culturais, quanto porque o conceito de sistema literário do autor permite que se contorne uma longa e, a meu ver improdutiva, discussão sobre a literatura infantil como um "gênero".

Um sistema literário, segundo Even-Zohar (2010), é constituído pela inter-relação de seis posições ou fatores, que o autor toma de empréstimo ao modelo de comunicação de Jakobson: o produtor, que não é apenas o autor de livros, mas todos aqueles que individual ou coletivamente lançam produtos como imagens e expressões no sistema; o consumidor, que também é mais que o leitor, podendo ser qualquer um que de uma maneira direta ou indireta consome os produtos literários; o produto, por sua vez, é a obra e igualmente expressões, imagens, modas, atitudes e modelos de vida que são elaborados dentro do sistema; o repertório, que corresponde ao conjunto de regras e demais referências orientadoras da produção, do consumo e da própria definição do que seja produto literário; a instituição, a qual responde pelas entidades e pelos demais elementos que, de uma forma ou de outra, regulam e controlam o sistema; o mercado, finalmente, que compreende todas as relações de consumo dentro do sistema. Além dessa formação interna, no sentido que pode ser delineada para cada sistema, um sistema literário é parte de um conglomerado de sistemas que Even-Zohar (2010) chama de polissistema e que nos permite compreender as relações dinâmicas que os sistemas culturais estabelecem entre si, a exemplo do posicionamento dado para uns em relação aos outros, conforme ocupem um espaço hegemônico ou dele se afastem.

Tendo como base a teoria do polissistema de Even-Zohar (2010), podemos ler a literatura infantil como um sistema dentro do polissistema literário e não apenas um adjetivo que recobre um gênero, uma segmentação etária ou uma classificação mercadológica, ainda que esses elementos estejam presentes na constituição do sistema literário infantil. Dentro do polissistema literário, a literatura infantil, quer por ter uma demarcação mais recente, quando comparada com outros sistemas literários, quer por manter histórica ligação com a escola, não ocupa uma posição central. Mas conseguiu estabelecer uma identidade de repertório que se fortalece progressivamente com as demandas de formação do leitor feitas pelas instituições e 


\section{pro.posıções}

pelos mecanismos de mercado. É isso que se pode depreender, por exemplo, das observações feitas por Lígia Cademartori (2010), uma reconhecida estudiosa da área. Para a autora, por ser situado entre a educação e a literatura, o lugar da literatura infantil no sistema literário sempre foi de uma "espécie de primo pobre" (Cademartori, 2010, p. 13). Graças a essa ligação com a escola, entretanto, criou-se "uma relação de dupla dependência entre a presença da literatura infantil nas escolas e a produção de livros desse segmento editorial pela indústria livreira" (p. 8), que, por um lado, levou a um crescimento expressivo de obras, consolidando o seu mercado; e, por outro, "atraiu autores que desfrutam do mais alto prestígio na crítica literária, integrantes do repertório de leitura dos adultos mais exigentes” (p. 14).

Por força da conjunção desses fatores, o sistema literário infantil passou a recobrir “diversas modalidades e processos textuais, tanto verbais quanto visuais" (Cademartori, 2010, p. 16) e adquiriu, nas últimas décadas, uma certa independência de seus pressupostos educacionais iniciais, passando "pelo que se pode chamar de internacionalização do gênero, resultado da globalização dos mercados” (p. 15). Nesse caso, as obras não são mais apenas mediadas pela escola e pela família, mas também pelos meios de comunicação de massa, implicando ainda em uma multiplicação de formas, via cinema e diversos acessórios, e associando-se à "moda e ao lazer" (p. 16) de forma mais intensa, ao participar do mercado de produtos infantojuvenis.

Tais características tornaram mais complexas as relações internas do sistema literário infantil, sobretudo no que tange aos seus usos educacionais que, naturalmente, sofrem transformações geradas pela própria consolidação do sistema em termos de mercado, produtores, instituições e repertório, que não podem mais ser vistos apenas na sua relação com a faixa etária do consumidor. Uma maneira de delinear essas transformações, processadas em dois diferentes momentos, consiste em verificar a morfologia que o sistema literário assume, a partir de sua relação com a educação. Antes, porém, é preciso inserir esse duplo processamento temporal dentro de um contexto, um quadro teórico-metodológico que ajude a ler a relação entre literatura e educação em seus próprios termos, tal como acontece com a concepção de letramento literário.

Paulino e Cosson (2009) definem letramento literário como "o processo de apropriação da literatura enquanto construção literária de sentidos” (p. 67). Ao detalhar a definição, os autores acentuam o caráter dinâmico e contínuo desse processo que acompanha 


\section{pro.posições}

o leitor desde o seu nascimento, transformando-se a cada novo contato com o universo da literatura, sem se restringir ao ensino formal. Também destacam que a leitura literária ou "construção literária dos sentidos" resulta de duas experiências imbricadas: "a interação verbal intensa” (p. 68), que é a inter-relação entre sujeito e linguagem feita por meio das palavras, por isso absolutamente livre e libertária, e "o (re)conhecimento do outro e o movimento de desconstrução/construção do mundo" (p. 69) que essas palavras demandam, ao levar o sujeito a dialogar com a experiência do outro e consigo mesmo.

No campo escolar, o letramento literário possui demandas específicas. A primeira delas é promover o encontro essencial do leitor com o texto, isto é, nada pode substituir, na formação do leitor, a experiência da leitura ou da escritura literária. Outra é compreender que a literatura é linguagem e, como tal, se espraia por diversas manifestações culturais além do livro, devendo todas elas ser acolhidas pela escola e trabalhadas segundo as suas características. Uma outra é que a experiência da literatura se dá em um contexto determinado, que é a sala de aula como uma comunidade de leitores, gerando um processo de compartilhamento de saberes e práticas, determinante para a construção de um repertório que é, ao mesmo tempo, pessoal e coletivo. Outra demanda, ainda, é que essa construção do repertório precisa ser guiada por meio de atividades sistemáticas e sistematizadas envolvendo a escrita, mas não restrita a ela, quando se busca proporcionar o desenvolvimento efetivo da competência literária, que é um dos objetivos centrais do letramento literário na escola (Cosson, 2006, 2014a, 2014b).

Em síntese, compreendemos, com Cowen (2009), que não só as pessoas se movem de um lugar para outro, mas também as ideias e as manifestações culturais, implicando nessa mobilidade não apenas transferências espaciais, mas, além disso, traduções e transformações que levam essas ideias e manifestações a assumirem uma nova morfologia por força da dinâmica desse movimento. Da mesma forma, compreendemos, com Even-Zohar (1990, 2010), que a literatura infantil constitui um sistema dentro do polissistema literário e, como tal, possui uma relação estreita com a educação, o que leva a uma certa distância entre ele e os sistemas mais voltados para o fazer 'puramente' artístico, como é o caso do sistema canônico central. Tal relação se torna progressivamente mais complexa à medida que esse sistema, por meio dos seus produtores, instituições, mercado e repertório, estabelece uma identidade que vai além dos produtos endereçados ao seu consumidor preferencial indicado no adjetivo. Compreendemos, ainda, com base na concepção de letramento literário de Cosson e Paulino (2009), que a relação do sistema literário infantil com a educação pode ser mais bem explicada, 


\section{pro.posições}

se inserida em um arcabouço teórico metodológico que equacione o lugar da literatura dentro do processo pedagógico, pois há questões específicas a serem observadas quando esse processo passa a acontecer no âmbito formal do ensino escolar. É com base nesses pressupostos que vamos delinear a seguir, em dois momentos, uma dupla morfologia da literatura infantil como um sistema cultural em movimento, pois articula a escola, a escrita, o livro e a formação do leitor como elementos estruturadores e estruturantes de sua relação com a educação.

\section{As relações anteriores}

No espaço da escola, o lugar da literatura infantil tem sido desde sempre associado ao aprendizado da escrita. Uma das formas mais tradicionais dessa associação consiste no aproveitamento histórico da literatura oral ou de textos da cultura popular como matéria de leitura das crianças, construindo um conjunto de produtos que valem mais pelo acesso que propiciam à escrita do que por suas eventuais qualidades estéticas. É assim que o repertório da literatura infantil na escola conta com gêneros como parlendas, adivinhações, lendas, mitos, contos populares, contos de fadas, fábulas, cantigas de roda, trava-línguas, quadras e cantigas de ninar. Tais gêneros constituem o que Jolles (1976) classifica como formas simples, porque antecedem a forma artística e são frutos da criação coletiva e guardados na memória da tradição oral.

Ao se transformarem em material de ensino escolar, esses gêneros da tradição popular ganham obrigatoriamente registro escrito e deixam de ser matéria de memória, para ser matéria de leitura, passando a existir ambivalentemente entre esses dois registros. Dessa forma, eles são valorizados como textos escritos, porque supostamente facilitam o reconhecimento das palavras, uma vez que, pelo caráter mnemônico próprio da literatura oral, a criança identificará com menor dificuldade a relação entre o som e a letra. Já como textos orais, são importantes porque são expressões que convidam ao jogo e à brincadeira com a língua, envolvendo facilmente as crianças justamente pela sua gratuidade e puerilidade.

Dessa forma, a literatura infantil no âmbito da escola assume uma morfologia que estabelece uma correspondência 'natural' entre a literatura para a infância e a infância da literatura. Mais que isso, o sistema da literatura infantil adquire uma feição de material de ensino que o distingue dos outros sistemas literários, sobretudo o canônico, que tem por 


\section{pro.posições}

princípios a autoria bem definida do produtor e a elaboração estética dos produtos. Essa marca pedagógica da literatura infantil compreende outros componentes, a exemplo da educação moral, do civismo e da socialização (Zilberman, 1985), porém é esse favorecimento do acesso da escrita que permanece implícita ou explicitamente com maior constância, ao longo do tempo, nos textos literários e nos usos pedagógicos deles, sobretudo quando associados ao processo de alfabetização. Nesse caso, a literatura infantil funciona como um dos mecanismos de fixação das convenções da escrita alfabética, a exemplo da forma das letras, da segmentação das palavras e da leitura da esquerda para direita, ao lado do desenvolvimento do vocabulário e de estruturas sintáticas formais da língua ligadas ao registro escrito.

Essa forte associação com a escrita não se faz sem consequências para o sistema literário infantil e para as práticas que a ele estão ligadas na escola. Uma dessas consequências é a limitação da literatura à escrita ou o fato de tomar a escrita como o único meio de expressão da literatura e o livro como a sua materialização por excelência. Trata-se de uma concepção até certo ponto paradoxal, quando se observa que não só parte dos gêneros da literatura infantil tem raízes e continua a existir via oralidade na literatura popular, como também várias das atividades de uso dos produtos da literatura infantil são essencialmente orais ou pictóricas, até mesmo porque a maior parte de seus consumidores não domina a escrita. Todavia, como o propósito final é levar ao domínio da escrita, justifica-se, por esse objetivo maior, a identificação limitadora da literatura com o texto impresso. Daí também o espaço garantido a certas obras que, por serem endereçadas às crianças e se destinarem a facilitar o processo de alfabetização, a exemplo de livros conceitos [concept books] e abecedários, terminam sendo adjudicadas ao sistema literário infantil pela escola, sem distinção e discussão de seu estatuto genérico e discursivo ${ }^{3}$. De certa forma, tais textos, assim como os vários paradidáticos que usam uma moldura ficcional para tratar de lições sobre meio ambiente, boa alimentação e comportamento social, integram o sistema literário infantil na escola apenas pelo fato de serem textos impressos com palavras e ilustrações, à semelhança dos textos com elaboração literária.

\footnotetext{
${ }^{3}$ Não estamos defendendo aqui uma fronteira que estabeleça limites entre o território dos textos literários e dos não literários, até porque compreendemos que um discurso só termina depois que outro começa, e que as identidades discursivas se dão pelos centros e não pelas fronteiras que são sempre porosas e contaminadas (Cosson, 2007). A intenção é chamar a atenção para uma produção de livros infantis que atualmente se avoluma e não pode ser simplesmente rotulada como literária, sem uma discussão de como participa do sistema da literatura infantil.
} 


\section{pro.posıções}

Outra consequência é a visão mesma de livro que se projeta a partir dessa associação. Nesse caso, o livro é, antes de qualquer coisa, um impresso com palavras que vão progressivamente se adensando, em uma correlação estreita entre a obra material e a idade, a escolaridade e o domínio da escrita por parte do leitor. É assim que as obras infantis "devem" ser de formato grande e diferenciado, conter poucas páginas, muitas imagens coloridas e poucas palavras, enquanto, contrastivamente, os livros para adultos são identificados pelo formato básico de um quarto de folha, sem ilustrações ou cores para além da capa. Dessa forma, um livro infantil só com palavras ou um livro para adultos com muitas imagens parecem contraditórios com o que eles deveriam materialmente ser. Igualmente, um leitor só é considerado verdadeiro leitor quando consegue passar de um tipo de impresso a outro, a quantidade de palavras e a presença de imagens e cores significando a menoridade ou a incapacidade do leitor de lidar com a escrita.

Também a formação do leitor é afetada, porque a ênfase é dada para a decifração do código, em detrimento de outras dimensões do ler. Não é sem razão, portanto, a estreita combinação entre atividades de ler e escrever, como se uma fosse necessariamente a contraparte da outra. Há, ainda, a preferência por textos curtos e sintaticamente simples, que facilitam a decifração, e por atividades que exploram a identificação de informações textuais, das quais as mais características são as fichas de leitura e os questionários. Além do mais, a competência leitora costuma ser medida em termos quantitativos - o leitor maduro é aquele que lê muitos livros -, ao mesmo tempo que se cultiva o receio de desperdício de tempo, quando a leitura visa “apenas" ao prazer estético (Silva, 1991) ou não tem um registro escrito correspondente.

Tudo isso faz da leitura literária das crianças uma atividade essencialmente escolar. Presa ao horizonte da escola, a literatura infantil assume uma morfologia genérica e textual, que busca, em primeiro lugar, assegurar o acesso e o domínio da escrita. Para atender a esse objetivo, a ligação do sistema literário infantil com os outros sistemas literários é enfraquecida, e são acentuados seus contornos de uso pedagógico.

\section{As relações atuais}

No Brasil, a partir dos anos 1970, o sistema literário infantil iniciou um processo de autonomização da escola (Zilberman \& Lajolo, 1986; Lajolo \& Zilberman, 1988) que vem se 


\section{pro.posıções}

consolidando até o presente. Não que os produtos do passado fossem apenas dirigidos à escola, como se sabe do pioneirismo de Lobato e seu Sítio do Picapan Amarelo (ainda que, compreensivelmente, tenha pagado seu tributo ao paradigma escolar com Emília no País da Gramática, entre outros) e da produção pontual de escritores consagrados, como Cecília Meireles, Vinícius de Morais e Érico Veríssimo. Todavia, é a partir dessa década que o sistema literário infantil escapa definitivamente do horizonte escolar, como são testemunhos os textos de Lygia Bojunga Nunes, Ana Maria Machado, Ruth Rocha e tantos outros produtores da literatura infantil, e adquire um funcionamento mais propriamente sistêmico, concluindo o ciclo da adaptação iniciado com a transferência do sistema no final do século XIX.

Um dos índices mais evidentes dessa nova morfologia da literatura infantil é a existência farta e variada de produtos dirigidos ao leitor criança, e não mais prioritariamente para o uso escolar. São obras que buscam dialogar diretamente com a criança, recusando o didatismo que se move para a seara dos livros paraliterários. Também a circulação dessas obras não se restringe à escola, nem é mais dependente da indicação dos professores ou dos bibliotecários. Agora outros espaços se abrem para ela, seja no âmbito da família, que se preocupa com a formação do leitor desde antes da idade escolar, seja nos espaços do mercado propriamente ditos, como se observa pelos setores especialmente dedicados à literatura infantil nas sofisticadas livrarias dos shopping centers e pelas editoras especializadas em publicar livros para crianças. Obviamente, esses novos espaços que caracterizam a expansão mercadológica da literatura infantil não conseguiriam se sustentar, se não fizessem parte de um movimento maior de construção do mercado infantil, no qual a criança assume o papel de consumidor autônomo. Nem por isso, entretanto, eles devem ser minimizados, porque efetivamente interferem no mercado do sistema literário infantil e o reconfiguram.

Mais livre em relação à escola, a literatura infantil escapa igualmente da escrita e do livro como sua única forma de expressão. Nesse sentido, registra-se, em primeiro lugar, a recuperação da VOz como meio legítimo de apresentação do texto literário, de que são testemunhas as oficinas de contação de histórias em bibliotecas, assim como a leitura em voz alta de textos literários para as crianças. Tanto é assim que a Hora do Conto se tornou modelar do uso oral da literatura infantil na escola. Independentemente da discussão entre o ler e o contar, em relação a essa atividade, está bem estabelecido o valor da oralidade como manifestação literária e seu papel fundamental na formação do leitor: “Ah, como é importante para a formação de qualquer criança ouvir muitas, muitas histórias. Escutá-las é o início da 


\section{pro.posições}

aprendizagem para ser um leitor, e ser um leitor é ter um caminho absolutamente infinito de descobertas e compreensão do mundo" (Abramovich, 1999, p. 14). Depois, a literatura infantil também passou a ser veiculada ou a participar de outras manifestações artísticas e culturais, como o cinema, a canção popular, os vídeos, as histórias em quadrinhos, inclusive com trocas e inspirando produtos em outros sistemas literários, como é o caso dos graphic novels.

Além disso, o próprio livro também se modificou, assumindo múltiplas formas de se constituir, com grande ênfase em sua materialidade e visualidade. Um exemplo são os livros destinados a bebês, crianças ainda não alfabetizadas ou em processo de alfabetização, que são feitos de materiais outros que não papel, como borracha e pano; ou os livros brinquedos, cujas páginas adquirem movimento e forma em montagens e dobraduras surpreendentes. Trata-se, assim, de "livros contemporâneos que apostam em performances visuais e sensoriais, os quais têm potencial para estimular nas crianças a transmissão de ideias por meio de suas formas, impressões/acabamentos, dobraduras dimensionais e significações múltiplas" (Ramos \& Paiva, 2014, p. 431). Mesmo quando o livro tem uma forma externa tradicional, a escrita que vem nas obras da literatura infantil já não segue a linearidade que 'encaminha' o leitor para o livro adulto. As palavras podem ocupar diferentes posições na página, insinuam-se entre as ilustrações, exigem que o livro seja virado de um lado para outro ou de ponta-cabeça, pedem para serem lidas juntamente com as ilustrações e até mesmo desaparecem, como acontece nos livros de imagens, ainda que sejam destinados a crianças já alfabetizadas.

Aliás, a visualidade é um dos campos em que a literatura infantil tem recebido grande investimento criativo. As ilustrações deixaram de ser apenas ilustrações, no sentido de que funcionavam como ornamento do texto, para ser uma camada a mais de sentido dentro do texto, ampliando o registro escrito e interferindo na leitura da obra. Esse diálogo entre a escrita e a visualidade se intensifica de tal maneira que já se faz necessária uma distinção entre livro com ilustração e livro ilustrado, compreendendo, no caso desse último, próprio da produção literária contemporânea, que se trata do "livro cujas imagens participam da construção da narrativa, sendo consideradas como elemento discursivo" (Belmiro, 2012, p. $852)$.

Além do alto investimento na forma e na visualidade que as obras passaram a apresentar, a formação do leitor é outro índice de grande relevância nessa nova morfologia do sistema literário infantil. Nesse caso, não só diminuiu o espaço das práticas teleológicas na 


\section{pro.posições}

escola, que tomavam a leitura da literatura infantil como preparação ou estágio para a leitura da literatura canônica, passando a leitura das obras infantis a valer por si mesma como experiência literária autêntica, como também mudou a própria forma de endereçamento ao leitor. Longe da atitude paternalista do adulto que aconselhava a criança ou assumia uma pretensa voz infantil para lhe passar informações, conduzindo a leitura e menorizando o leitor, os textos ficaram mais complexos do ponto de vista da elaboração e passaram a demandar uma leitura interpretativa que vai além da simples decifração ou localização de informação. Além disso, como a leitura dos textos da literatura contemporânea exige que se integrem imagem e letra em um todo coerente que é a obra, as práticas escolares de formação do leitor também precisam ser modificadas, uma vez que “o interlocutor, ao ler, precisa estar atento a essas linguagens, interagindo com as mesmas e relacionando-as para atribuir sentido ao texto", ou seja, demandando "um leitor competente, capaz de interagir com palavra e ilustração na significação da obra” (Ramos, Panozzo, \& Zanolla, 2011, p. 247).

Para exemplificar essa nova morfologia do sistema literário infantil, propomos uma breve análise da obra Bruno e Amanda: histórias misturadas, de Pedro Veludo (2013), com ilustração de Henrique Koblitz, que demonstra em termos concretos algumas das características que delineamos anteriormente, com destaque para a visualidade e a elaboração textual.

\section{Novos diálogos com o leitor infantil:}

\section{o amor, a aventura e o livro}

À primeira vista, o livro Bruno e Amanda: histórias misturadas poderia ser considerado uma obra tradicional no universo da literatura infantil. Afinal, trata-se de um livro com tamanho de uma folha A4, com apenas 42 páginas, ilustrações bem coloridas e uma trama que envolve princesa, feitiço, mapa de tesouros e códigos secretos. Todavia, as similaridades não vão muito além e até mesmo esses elementos comuns são reelaborados de forma reveladora sobre as possibilidades de criação literárias exploradas contemporaneamente.

A principal inovação da obra de Veludo está em sua composição que "mistura" três histórias - uma sobre uma princesa que perdeu o sorriso, outra sobre um menino caçador de aventuras e uma terceira que incorpora as duas, comentando a escritura delas. Por meio desse artifício de encaixe, o texto abre espaço para múltiplas leituras, ao mesmo tempo que joga com 


\section{pro.posições}

as expectativas de diferentes leitores ${ }^{4}$. De certa forma, trata-se de uma obra em reverso daquilo que aparentemente promete ser, mas nem por isso se torna uma narrativa deceptiva, pois a narração enreda o leitor em novas descobertas. Já na capa se anuncia essa estratégia, ao se mostrar uma estante com destaque para três livros: ao centro um grosso dicionário da língua portuguesa, que tem, à esquerda, um volume mais fino intitulado $\mathrm{O}$ mistério do sumiço do sorriso da princesa Amanda e, à direita, um livro um tanto mais volumoso, com o título Os mapas de Bruno. A identificação dos títulos dos três livros permite que o leitor construa hipóteses sobre quais são as histórias misturadas, além de indicar o conteúdo fabuloso de duas delas pelas palavras "princesa" e "mapas".

O miolo do livro marca visualmente as histórias, conforme as convenções sociais de seus protagonistas. A narrativa sobre a princesa Amanda é escrita com letra cursiva, como se fosse um diário de menina, com fundo suavemente colorido e predomínio de azul e verde nas cores das ilustrações. Já a narrativa sobre o aventureiro Bruno vem sobre um fundo sépia, como se fosse um pergaminho ou papel envelhecido, com tipo de letra antigo e mais condensado, além de ilustrações com cores predominantemente terrosas, remetendo a textos antigos. A narrativa sobre a narrativa possui o registro das obras comuns, aquelas que tratam do cotidiano ou realidade, tipo Times New Roman e fundo branco, com ilustrações que combinam as cores das duas outras narrativas. As páginas das histórias de fadas e aventuras, até porque não têm final na obra e são fruto da fantasia, não são numeradas, ao contrário das páginas da narrativa de moldura, que são numeradas, a indicar que representam a realidade da narração.

O texto escrito, por sua vez, recusa as convenções narrativas e as demarcações excessivas das posições de gênero comuns na literatura infantil, fazendo as histórias brincarem com as convenções que supostamente anunciam. Os mapas de Bruno, por exemplo, não levam a um tesouro convencional, e as suas aventuras se fazem pelas palavras, desconstruindo o estereótipo dos livros para meninos com narrativas de ação. Do mesmo jeito, a princesa Amanda não perde seu sorriso por questões sentimentais, mas, como o texto mais tarde explicita, porque a tristeza faz parte da vida, e é importante não permitir que ela nos domine. Também o presente de Bruno para a princesa é uma prosaica bala e são as palavras que ajudam a recuperar seu sorriso. Nem mesmo o final feliz escapa, pois o narrador "não sabe"

\footnotetext{
${ }^{4}$ Registramos e agradecemos aqui a preciosa colaboração da Profa. Cíntia Schwantes, que, a partir de uma discussão conosco, elaborou uma análise da obra, em grande parte reproduzida nessas breves considerações que fazemos sobre Bruno e Amanda: histórias misturadas.
} 


\section{pro.posições}

como termina a história e deixa a questão em aberto para o leitor resolver. Com isso, a obra consegue unir com habilidade todas as camadas da narrativa, fazendo que cada uma dependa da outra para ser compreendida, ao mesmo tempo em que apresentam suas peculiaridades.

Todo esse entrelaçamento e jogo com convenções narrativas que a obra promove podem parecer complexos demais para um leitor infantil. Entretanto, a criatividade e a sensibilidade com que a obra foi elaborada permitem que possíveis dificuldades de interpretação sejam facilmente transponíveis. Afinal, respeitando e reconhecendo a tessitura cultural em que se encontra imersa a criança contemporânea, a sua matéria-prima é justamente o poder da palavra feita literatura.

\section{Para refletir: qual leitor, ensino da literatura e}

\section{formação de leitor em nossa sociedade pós-literária?}

As transformações pelas quais o sistema literário infantil passou e continua passando não podem ser dissociadas, como já chamamos a atenção, da criação de um mercado de consumo infantil autônomo e da reconfiguração cultural da literatura e da escrita em uma sociedade pós-literária. É justamente por isso que o seu exemplo pode nos ajudar a refletir sobre o lugar do leitor, os desafios de sua formação e a necessidade do ensino de literatura contemporaneamente.

Como um sistema que se movimenta e assim modifica a sua morfologia, a literatura infantil tem sua origem ligada à transferência dos textos da literatura oral para o ambiente da escola junto com a nova identidade social da criança (Zilberman, 1985). Na condição de material de ensino, as obras literárias são marcadas, entre outros aspectos, por uma estreita associação com a escrita, subordinando-se ao seu aprendizado. Essa forma de tradução da literatura oral tende a apagar suas características literárias em favor do seu uso pedagógico. Aos poucos, entretanto, o investimento na ludicidade e na fantasia terminam se sobressaindo em novos produtos literários, indicando a transformação da literatura infantil em um sistema literário autônomo, ainda que muito presente na escola.

A transformação da morfologia da literatura infantil se revela, sobretudo, na superação de seus fins educacionais imediatos em favor de uma maior elaboração literária de seu repertório, por meio do qual incorpora e legitima a nova configuração do sistema. É isso que 


\section{pro.posições}

se pode registrar com a ampliação da circulação das obras literárias para outros ambientes que não a sala de aula. É também o que se observa em obras que pressupõem uma interação direta com o leitor, dispensando ou secundarizando a mediação escolar. É o que se revela, ainda, na presença da literatura em outras manifestações artísticas ou veículos que não apenas o livro, como a recuperação da oralidade com a contação de histórias, as histórias em quadrinhos, os filmes e as canções populares especialmente endereçados à criança. $\mathrm{O}$ próprio livro assume múltiplos formatos e forte investimento na visualidade, de tal maneira que, como bem destaca Celia Belmiro (2012),

o que temos visto ultimamente de produção literária dirigida a crianças se tem apoiado em tantas outras linguagens, no aguçamento de sensações táteis, olfativas, visuais, sonoras, que a obra literária para a infância (ou a sua definição) ultrapassa o relato verbal. (p. 846)

Todas essas modificações no produto ensejam, naturalmente, uma nova relação com o consumidor. Ultrapassando a referência simplificadora à idade e à escolaridade, o leitor da literatura infantil se torna tão múltiplo quanto as obras que lhe são endereçadas e demanda uma nova formação, que se preocupe mais com a sua competência literária do que com a aquisição da escrita. Até porque ler literatura infantil não pode ser mais visto como um estágio para qualquer outra coisa, mas sim como uma experiência literária autêntica.

Tudo isso nos mostra que já não podemos pensar o leitor apenas como um usuário privilegiado da escrita. Em uma sociedade pós-literária, o leitor é um intérprete do mundo, ou melhor, o ato de ler se torna uma competência humana tão essencial que restringi-lo à tecnologia da escrita é empobrecê-lo e não compreender a sua verdadeira dimensão na ordem do ser. A formação do leitor passa pela escrita, mas não se detém nela e em nenhuma outra tecnologia - antes precisa integrar todas elas, compreendendo que o mesmo sujeito ocupa os papéis de leitor, espectador e internauta (Canclini, 2008), e é para o exercício consciente desses papéis que a escola deve direcionar seus esforços pedagógicos. A literatura é palavra, uma linguagem que expressa o simbólico, que nos dimensiona como humanos e não está apenas nos livros, nem mesmo apenas na escrita, por isso é preciso buscar e compreender como a literatura funciona em outros meios, modos e sistemas culturais. A escola precisa reconhecer a literatura em toda essa multiplicidade, ainda que não possa esquecer a longa tradição que a identifica com a escrita e com o livro como seu veículo preferencial. 


\section{pro.posıções}

ISSN 1980-6248

Em suma, enquanto horizonte de reflexão para as nossas questões sobre qual o lugar do leitor, sobre o modo de formar um leitor atualmente, sobre a razão para se continuar a ensinar literatura contemporaneamente, a dupla morfologia do sistema literário infantil nos indica que a literatura, mesmo em uma sociedade pós-literária, continua fundamental, tal como diz Even-Zohar em nossa epígrafe, para que os membros dessa sociedade consigam construir os caminhos que os levem para o futuro desejado, os caminhos que dizem sobre o que se quer ser e como se quer ser humano, os caminhos que mostram como construímos e devemos construir a nós e a nossas comunidades.

\section{Referências Bibliográficas}

Abramovich, F. (1999). Literatura infantil: gostosuras e bobices (3a ed.). São Paulo: Scipione.

Bell, D. (1974). O advento da sociedade pós-industrial. São Paulo: Cultrix.

Belmiro, C. A. (2012). Narrativa literária: suporte para a infância, texto para a juventude. Perspectiva, 30(3), 843-868. Recuperado em 04 de agosto de 2015, de $<$ https://periodicos.ufsc.br/index.php/perspectiva/article/view/2175795X.2012v30n3p843/24383>.

Cademartori, L. (2010). O que é literatura infantil (2a ed.). São Paulo: Brasiliense.

Canclini, N. G. (2008). Leitores, espectadores e internautas. São Paulo: Iluminuras.

Candido, A. (1975). Formação da literatura brasileira (5a ed.). Belo Horizonte: Itatiaia; São Paulo: EDUSP.

Candido, A. (1987). A educação pela noite. São Paulo: Ática.

Castells, M. (1999). A sociedade em rede. São Paulo: Paz e Terra.

Coelho, N. N. (1991). Panorama histórico da literatura infantill juvenil. São Paulo: Ática.

Cosson, R. (2006). Letramento literário: teoria e prática. São Paulo: Contexto.

Cosson, R. (2014a). Círculos e leitura e letramento literário. São Paulo: Contexto.

Cosson, R. (2014b). Letramento literário. In I. C. A. Frade, M. G. Val, \& e M. G. Glossário Ceale: termos de alfabetização, leitura e escrita para educadores. Belo Horizonte: UFMG/Faculdade de Educação. 


\section{pro.posıções}

ISSN 1980-6248

Cowen, R. (2009). The transfer, translation and transformation of educational processes: and their shape-shifting. Comparative Education, 45(3), 315-327.

Drucker, P. (1997). Sociedade pós-capitalista (6a ed.). São Paulo: Pioneira.

Even-Zohar, I. (1990). Polysystem studies. Poetics today, 11(1), 1-269.

Even-Zohar, I. (2005). Polysystem theory (revised). Papers in culture research, 38-49.

Even-Zohar, I. (2010). Papers in culture research. Tel Aviv: Porter Chair of Semiotics. Recuperado em 10 janeiro de 2015, de http:// citeseerx.ist.psu.edu/viewdoc/download?doi=10.1.1.477.787\&rep=rep1\&type $=\mathrm{pdf}$

Ferreira, A. G. (2008). O sentido da educação comparada: uma compreensão sobre a construção de uma identidade. Educação, 31(2). Recuperado em 15 fevereiro de 2015, de

http://revistaseletronicas.pucrs.br/ojs/index.php/faced/article/download/2764/2111

Jolles, A. (1976). As formas simples. São Paulo: Cultrix.

Lajolo, M., \& Zilberman, R. (1988) Literatura infantil brasileira: história e histórias (4a ed.). São Paulo: Ática.

Larsen, M. A. (2010). New thinking in comparative education: Honouring Robert Cowen. Rotterdam: Sense Publishers. Recuperado em 15 de fevereiro de 2015, de https://www.sensepublishers.com/media/693-new-thinking-in-comparativeeducation.pdf

Malet, R. (2004). Do Estado-Nação ao Espaço-Mundo: as condições históricas da renovação da educação comparada. Educação \& Sociedade,25(89), 1301-1332. Recuperado em 15 de fevereiro de 2015, de http://www.scielo.br/pdf/es/v25n89/22622.pdf

Marques, J. O. D. A. (2002). Sobre as regras para o parque humano de Peter Sloterdijk. Naturęa bumana, 4(2), 363-381. Recuperado em 20 de março de 2015, de http:// pepsic.bvsalud.org/scielo.php?pid=S1517$24302002000200005 \&$ script $=$ sci_arttext\&tlng=en

Masuda, Y. (1980). A sociedade da informação como sociedade pós-industrial. Rio de Janeiro: Rio/Embratel. 


\section{pro.posições}

ISSN 1980-6248

Mattelart, A. (2002). História da sociedade da informação. São Paulo: Loyola.

Mayos, G., \& Brey, A. (Eds.). (2011). La sociedad de la ignorancia. Barcelona: Editorial Península. Recuperado em 15 de fevereiro de 2015, de http://www.infonomia.com/pdf/sociedad_de_la_ignorancia_es.pdf

Paulino, G., \& Cosson, R. (2009). Letramento literário: para viver a literatura dentro e fora da escola. In R. Zilberman, \& T. Rösing (Orgs.), Escola e leitura: velha crise; novas alternativas. São Paulo: Global.

Ramos, F. B., \& Paiva, A. P. M. (2014). A dimensão não verbal no livro literário para criança. Contrapontos, 14(3), 425-447. Recuperado em 04 de agosto de 2015, de <http://www6.univali.br/seer/index.php/rc/article/download/5919/pdf_45>

Ramos, F. B., Panozzo, N., \& Zanolla, T. (2011). Imagem e palavra na leitura de narrativa. Perspectiva, 29(1), 245-262. Recuperado em 04 de agosto de 2015, de $<$ https://periodicos.ufsc.br/index.php/perspectiva/article/view/2175795X.2011v29n1p245/19427>.

Silva, E. T. (1991). O ato de ler: fundamentos psicológicos para uma nova pedagogia da leitura. São Paulo: Cortez; Autores Associados.

Sloterdijk, P. (2000). Regras para o parque bumano: uma resposta à carta de Heidegger sobre o bumanismo (J. O. de A. Marques, trad.). São Paulo: Estação Liberdade. Touraine, A. (1970). Sociedade pós-industrial. Lisboa: Moraes.

Veludo, P. (2013). Bruno e Amanda: histórias misturadas. São Paulo: Quatro Cantos.

Zilberman, R. (1985). A literatura infantil na escola (5a ed. rev. ampl.). São Paulo: Global.

Zilberman, R., \& Lajolo, M. (1986). Um Brasil para crianças: para conhecer a literatura infantil brasileira: histórias, autores e textos (2a ed.). São Paulo: Global.

Submetido à avaliação em 04 de janeiro de 2016; aceito para publicação em 11 de abril de 2016. 